\title{
Operationalising social investment: from policy dimensions to ideal-types
}

\author{
Lisa Andersson \\ Department of social work, Stockholm University, Stockholm, Sweden
}

\begin{abstract}
Social investment in Europe has primarily been measured by studying expenditure data from specific categories of social policy. This article argues that we need a more nuanced way of studying the presence of social investment, and develops a tool for measuring the ideational content of social investment in policy regulations. By operationalising three key policy dimensions of social investment; time, distribution and policy coherence, varying approaches of social investment are discerned, landing in the development of three ideal types: a strict social investment, a targeted social investment and a reactive social investment. To demonstrate its application, the social investment ideal-types are applied to cases of policies for unemployed youth in different European countries. The operationalisation and ideal types presented in this article provide a structure and nuance to the understanding and measuring of social investment, aiding in the further debate on its pros, cons and presence in European social policy.
\end{abstract}

\section{ARTICLE HISTORY}

Received 17 May 2017

Accepted 11 April 2018

\section{KEYWORDS}

Social investment; social policy; ideal types; policy regulations; youth unemployment

\section{Introduction}

The concept of social investment is of growing importance to theory and practice in social policy. Social investment is often described as an agenda responding to new social risks, an increasingly knowledge- and service based economy and labour market. It aims to reduce intergenerational poverty and increase social inclusion, by sufficiently equipping people to gain employment and face social risks. This implies focusing policy efforts toward investments in human capital, child-care and education and making work pay (Jenson, 2009; Morel, Palier, \& Palme, 2009).

Much of the literature on social investment is focused on either concluding whether countries in Europe have implemented social investment policies, studying the outcome of social investments or critically debating the concept. Most of this literature concludes that Europe has not entered into an age of social investment for better or worse. However, this does not mean that we are at a standstill, or that studies of policy development with the social investment concept in mind are uninteresting. There are some recent

CONTACT Lisa Andersson lisa.andersson@socarb.su.se @ Department of social work, Stockholm University, Stockholm 106 91, Sweden

(c) 2018 The Author(s). Published by Informa UK Limited, trading as Taylor \& Francis Group

This is an Open Access article distributed under the terms of the Creative Commons Attribution-NonCommercial-NoDerivatives License (http://creativecommons.org/licenses/by-nc-nd/4.0/), which permits non-commercial re-use, distribution, and reproduction in any medium, provided the original work is properly cited, and is not altered, transformed, or built upon in any way. 
studies aiming to develop and highlight distinguishing traits of social investment. Kvist (2015a) for example, centres on the life-course perspective of social investment as a central dimension. The article points out that social investments build on generational contracts, meaning that generations have different positions during the life course, from being recipients of welfare policies as children and youth, to being contributors in working age, and recipients again in old age. It also emphasises that investments at different stages of the life-course have implications for stages to come, and depend on previous stages. The last comment is emphasised as a central component to the understanding of social investment in other recent social investment articles as well (Bengtsson, de la Porte, \& Jacobsson, 2017; Leoni, 2016). However, the novelty of recent debates about the ideas and content of social investment is yet to be operationalised into measurable variables. Over time, attempts to measure social investments have relied heavily on expenditure data (Bengtsson et al., 2017; Bonoli, 2009; Kouitto, 2016; Leoni, 2016). And while there are efforts to create more precise variables, the operationalizations often create binary categories of social investment or non-social investment policies. Lacking are measurements of social investments that are more nuanced in the understanding of the concept, and measurable in other ways than through the use of expenditure data.

The notion that ideas matter when we study policy change is not new (Beland, 2016). By studying the ideational content of policies, we can gain insight into developments and changes in welfare states. Social investment as an orientation for policy development spans over a broad range of areas, with an extended perspective on time in its overarching goals. It is the conjecture of this article that such characteristics imply that there is a variety of social investment policies. The aim of this article is to develop a tool for measuring such variations of social investment approaches in regulations of policies. The method for operationalising the ideational content of social investment, builds on Sartori's (1970) ladder of abstraction. The ladder of abstraction serves as a method for operationalising a concept on several levels. Sartori's original model (1970) presents three levels of abstraction: high (superordinate) level categorisation, medium level categorisation and low level categorisation. A high level constitutes the superordinate concept that one wants to operationalise, at this level the concept is defined by less specific attributes and is thereby the most inclusive level where the concept has a wide scope. A medium level establishes those dimensions that make up the superordinate concept, it determines which 'worlds' it belongs to. Lastly, at a low level the concept is defined by empirically observable attributes. The different levels of abstraction range from less specific attributes and greater inclusiveness, toward more specific attributes and a narrower scope. As suggested in recent studies on welfare state development and social investment, it is important to acknowledge and consider that contextual and institutional settings of different countries shape the ideas of social investment as they are implemented (Ellison \& Fenger, 2013). While this article is not an empirical analysis, but rather presents a concept development and proposition of how future studies can measure social investment empirically, the importance of contextual factors in such studies are recognised as important. When applying the model to an empirical analysis, the patterns that emerge may reflect diverging institutional and contextual settings in different countries and types of welfare states. The different variables that are established in the operationalisation could certainly be impacted by how welfare state institutions are constructed and function. When applying the model in an empirical analysis it would therefore be both possible, and advisable to make use of theoretical tools regarding contextual factors that may impact policy development. 
To make the operationalisation more tangible I have chosen to relate it to a specific group and risk, namely young people at risk of unemployment. Efforts toward youth and the risk of becoming or being unemployed are closely associated with what social investment strategies must respond to. ${ }^{1}$ While young are a heterogeneous group, this still implies a narrowing of the scope.

A common way of measuring social investment efforts has been to use expenditure data. While it is both accessible and provides big data sets for comparison, it has been argued problematic for several reasons. As outlined by Van Oorschot (2013), categories of expenditure may be quite rough, and conclusions that more expenditure equals better provision must first consider the size of the target group, economic performance of the country, administrative policy costs etc. These studies may serve well as rough indicators of welfare state generosity (Bonoli, 2007), but I would claim they do little to unravel the ideas and approaches inherent in welfare state policies.

Prior attempts to measure social investment using expenditure data, have identified specific categories of policies as social investments by default (Bengtsson et al., 2017; Bonoli, 2009; Bouget, Frazer, Marlier, Sabato, \& Vanhercke, 2015; Kouitto, 2016; Van Kersbergen \& Hemerijck, 2012; White, 2012). These studies bring valuable insight into what the policy landscape looks like, related to policy types often described as social investments. Lacking however is knowledge of the approaches represented in these policies, their ideational content. This is something which cannot be discerned by simply studying the prevalence of specific policy categories. Whether, and to what extent a policy can be considered social investment oriented is therefore not the starting point of this article, but the task itself. Still it is important to state that this represents one way of operationalising the concept of social investment. With this effort, I hope to bring some insight into how the main approaches of social investment can be defined and operationalised, and what types of social investment can be imagined.

The article begins by introducing social investment, followed by identifying three central dimensions of the concept. Then follows an operationalisation of said dimensions into variable-settings, exemplified by applying them to empirical cases of policies targeting youth unemployment. In the final section I identify and discuss different profiles of social investment based on the different variable settings, and relate them to the policy examples.

The analytic exercise in this article remains at the level of policy regulations, outlining the programmes' policy content, access and administration. For further conclusion on programmatic developments toward social investment, aggregated data on policies would be required.

\section{Framework and outline}

This article focuses on the level of formal policy regulations, and the risk-category youth and unemployment. Youth are defined in accordance with EU indicators (European Commission, 2011) as 15-24 year olds. The focus on youth and unemployment relates to the pressing issue of high youth unemployment rates in Europe, combined with the social investment focus on employment, and on young people and preventive measures. The article's European perspective is a consequence of the debate on social investment both politically and scholarly being related largely to the European context. 
In order to provide a backdrop against which the ideas of social investment can be related, the variables are contrasted to previous welfare state ideas. One of the important contributors to the debate on social investment, Jane Jenson (2009), undertakes a mapping of social investment-, Keynesian- and Neo-liberal ideas, claiming that social investment has a logic that differs from the other two. She describes Keynesian ideas as prescribing state responsibility for assuring protection in the present when markets fail, and providing equal opportunities for its citizens, through a hierarchical and bureaucratic form of governance. In contrast the neoliberal perspectives is described as advocating limited state responsibility for welfare in order to avoid future deficits, governance through corporate models and privatisation, and a view on inequality as inherent to and necessary in the free market (Jenson 2009). It is based on these descriptions that I refer to Keynesian and Neoliberal welfare state ideas throughout this article.

\section{The concept of social investment}

Following the ladder of abstraction, at the high level of categorisation the concept of social investment can be described both as a paradigm, a normative framework and a policy agenda. Early conceptual designs of social investment advocated policies moving from what was perceived as passive benefits, toward more active labour market policies combined with human capital investments. The main message being that social policy should be treated as a productive factor, given that spending on the right forms of social policy would come to pay off at a later stage (de la Porte \& Jacobsson, 2012; Jenson, 2009; Morel et al., 2009). Still, this is a somewhat ambiguous definition of what social investment really means. This ambiguity can partly be traced back to the two conflicting perspectives on social investment brought forward during the 90's, when the concept emerged (Jenson, 2009). In the early 90's Anthony Giddens and Tony Blair presented it as a way of wedding together ideas from a neo-liberal and a social democratic welfare state agenda (Giddens, 1998). In the late 90's, Esping-Andersen spearheaded a group of scholars assigned by the EU to submit a report regarding the welfare state of the twenty-first century. The report (Esping-Andersen, Gallie, Hemerijck, \& Myles, 2002), promoted a more social-democratic oriented version of the social investment concept (Hemerijck, 2012). And while it has by some been promoted as a route to lobbying for social expenditure, there was already in the early social investment literature of Giddens (1998) and Esping-Andersen et al., (2002), a dividing line between whether and how social investment policies should include, or preclude spending on social protection (Esping-Andersen et al., 2002).

Today, there is among scholars a 'tug-of-war' between the up- and downsides of social investment. On the one hand there is the potential of social investment to underpin a platform for increased social equity and reduced intergenerational poverty (Bothfield \& Roualt, 2014; Deeming \& Smyth, 2015; Hemerijck, 2011; Nolan, 2013). On the other hand the risk of detrimental consequences such as social security cuts or a 'race-to-thebottom', Matthew-effects and reproducing social stratification (Bothfield \& Roualt, 2014; Cantillon, 2011; Nolan, 2013). Not to mention the concerns of what an economic normative rationale for spending on social policies means (Nolan, 2013). Tied into this is the exclusion-critique that not all individuals can and/or will enter the regular labour market, begging the question how they may be included in a social investment agenda 
(Cantillon \& van Lancker, 2013). Parts of the literature is also concerned that there is a trade-off between social policy and social investment spending (Cantillon \& van Lancker, 2013). It is however, as emphasised by Nolan, problematic to make such arguments the centre of a conceptual discussion without being able to clearly define which policies constitute an investment. Such a task involves more than simply making up one's mind in an arbitrary fashion; rather it needs to be robust in its logic and applicability (Cantillon \& van Lancker, 2013).

So what are the central dimensions of social investment? An absolutely key dimension of social investment is the temporal perspective. It is emphasised in the literature that investment must begin at the early stages of life to equip people for life in a contemporary economy by providing for example child-care, education and skill upgrading in order to pre-empt for example unemployment. This implies preventing, as opposed to simply repairing the consequences of social risks through cash-benefits (Esping-Andersen et al., 2002; Hemerijck, 2015; Morel et al., 2009). As pointed out by Esping-Andersen et al. (2002), and Vandenbroucke and Vleminkx (2011), social investment strategies should be biased toward the preventing of social risks through building and enhancing human capital. While this position is perhaps most prominent in the literature, it is not the only one. It is also argued that a social investment agenda cannot wholly be without repairing policies. The preparing aspect of social investment is often in the literature connected to the provision of equal opportunities. But scholars also mention the need for equal outcomes. These equality approaches represent the relevant Distributional principle of social investment, referring to what needs to be provided by and for whom, in order to achieve better life-chances and social inclusion. It thereby presupposes an approach to equality, but it also alludes to how responsibilities of provision are to be distributed. The social investment literature also emphasises the importance of a broad battery of policies (Hemerijck, 2015). Different periods of the life-course require policy-efforts in several policy areas (Hemerijck, 2015). The relevant policies and policy areas are repeatedly described as interdependent, emphasising the important role of institutional conditions. Social investment policies need to be mutually reinforcing and cohesive (Cantillon, 2011; Esping-Andersen et al., 2002; Morel et al., 2009; Vandenbroucke \& Vleminkx, 2011), reflecting the central role of policy coherence for social investments. These three dimensions; temporal perspective, distributional principle and policy coherence are recurring and central to the understanding of what approaches underpin the concept and are thus our starting point in the attempt to operationalise the ideas of social investment.

\section{Policy dimensions of social investment}

Based on the described distinctive features of the concept, this section will elaborate on the three dimensions of social investment:

- Temporal perspective

- Distributional principle

- Policy coherence

Within each dimension, there are different approaches that are more or less in-tuned with social investment ideas. It is the combination of an approach to time, distribution and 
coherence in policies that determine if and how they can be considered social investments. In other words, these are our independent variables of social investment.

\section{Temporal perspective}

Investing in people is perhaps the most salient idea promoted in social investment literature, (Bengtsson et al., 2017; Bonoli, 2009; Hemerijck, 2011; Morel et al., 2009). The idea is that allocating resources to policies that are capacity building for individuals will reduce the prevalence of risks such as unemployment in the future. I.e. it has to do with how policies relate to the occurrence of social risks, in this respect social investment differs from the welfare regimes of the past. As described by Jenson (2009) in her portrait of modern citizenship-regimes, Keynesian policies responded directly to the risks of the present, the neo-liberal politics on the other hand focused on constraining costs in the present to avoid risks brought on by deficits in the future. The timeline of social investment also extends from the present into the future, yet with the distinct difference of a reversed logic of spending (on investments), rather than saving, in the present given the assumption that such spending will materialise as revenue in the future.

While the social investment perspective is biased toward preventive policy responses equipping the individual to avoid or handle social risks, the literature also speaks of striking a balance between proactive and reactive policies (Vandenbroucke \& Vleminkx, 2011; Esping-Andersen et al., 2002; Giddens, 1998). Without reactive measures individuals may under certain circumstances not be able to make use of their capital or worse yet, it may be depleted. For example, income security will most likely affect the level of flexibility of workers (Bothfield \& Roualt, 2014; Hemerijck, 2015). Hemerijck (2015) describes reactive policy measures in the realm of social investment as a form of protective buffers during periods of volatility and transition in people's lives. This implies that such periods will be brief or only occur occasionally, given that the role of reactive policies should still be marginal to that of proactive policies. Or that some degree of materialised risk is negligible in a social investment agenda. In fact, in Anthony Giddens (1998) social investment, proactive measures would preferably replace reactive cash-benefits in all areas possible.

\section{Distributional principle}

The distributional principle here refers to perspectives on responsibility and equality, or simply who should provide what to whom? Based on a dichotomous classification of equality-approaches, equal opportunities imply equal shares distributed for all, while equal outcomes seek to distribute resources in a way where the end result is as equal as possible (Dworkin, 1981a, 1981b). Neo-liberalism favours diversity as inherent to the free-market and a means to control spending, as opposed to Keynesianism that favours equal opportunities (Jenson, 2009). Social investment is primarily characterised by distributional principles of a more individualistic nature, promoting equal opportunities proactively. Equipping the individual and aiding him/her to become better skilled for new types of jobs in an increasingly flexible labour market is often described as a central task of a social investment strategy (Bonoli, 2009; Vandenbroucke, Hemerijck, \& Palier, 2011). Bringing us to the issue of responsibilities of state and individual/ family for different perspectives on equality. The approach to equality in social 
investment implies that the primary responsibility for policy makers (the public sphere) is to provide equipping and preparing efforts on broad front through different life stages, while the further outcome is the responsibility of the individual/the family (private sphere) (Jenson, 2009). A system of broadly distributed social policies, rhymes with the notion of universalism in welfare state theory. It could therefore be argued that much of the social investment literature is in fact suggesting that social investments to a large part should lean toward a more universalistic provision of policy. However, social investment also mentions the complementary role of policies that protect in the face of social risks, unemployment for example (Vandenbroucke \& Vleminkx, 2011), targeting those that need it more. Such policies reflect an approach to equal outcomes, but lie closer to the Keynesian welfare state ideas (Vandenbroucke \& Vleminkx, 2011). In these instances, the public has a responsibility to address inequalities. This means that the condition for such responsibility is substantive inequality, hence this responsibility is only toward already marginal(ized) individuals with the goal of increasing equal outcomes.

\section{Policy coherence}

A broad battery of policy responses is part of a social investment agenda. This is exemplified in the social investment literature by calls for policy efforts toward skill enhancement and full employment; women entering the labour market, early education and childcare (Bothfield \& Roualt, 2014; Cantillon, 2013; Deeming \& Smyth, 2015; Hemerijck, 2011; Jenson, 2009; Pintelon, Cantillon, Van den Bosch, \& Whelan, 2013). The assumption in social investment literature is that these policies impact and has bearing on one another, making coherence of policies important. While such complementarity is possible, as put by Atkinson (2010) it 'can be achieved but not assumed'. This ties in to some of the critical voices of this concept, arguing that in a worst-case scenario incoherent policies may generate 'Matthew effects' where measures benefit those among the target group who are already better off (Cantillon \& van Lancker, 2013). So for situations or groups where problems are complex, coherence will likely have a crucial impact on the extent to which policies reach and aid the disadvantaged. Yet there is a lack of clarity as to what precisely will generate policy-coherence. One aspect of coherence, it can be argued, is the interaction and cooperation between policy areas. Scholarly literature in this field indicates that provision of a multitude of policies including services, cash and in-kind benefits from several areas and actors will likely require coordination (Øverbye, Strohmeyer Navarro Smith, Karjalainen, \& Stremlow, 2009). Even more so if there are common goals to the provision of such policies. This relates well to social investment and its coherence idea. An expression of coherence could thus be regulations of how coordination between policy areas and actors is organised, for example if there is required cooperation or even gathering different agencies under common leadership or in common facilities. Related to welfare state paradigms, the neo-liberal ideas entail differentiation of policy provision, organisationally dispersed among decentralised levels and a multitude of actors (Jenson, 2009). Keynesian notions of policy organisation and state interventions on the other hand, promote macro-level management implying some mode of centralisation (Jenson, 
2009). In this sense the social investment notion of policy coherence seem, while vague, to be a step away from both Keynesian and neo-liberal thinking.

Notable in this section is the room for variation along the lines of social investment ideas within each dimension, and how the ideational content between dimensions connect and overlap. The proposed framework therefore allows for different approaches to time, distribution and coherence, and at the same time indicates that how the approaches are combined has bearing on the extent and form of social investment.

\section{Defining variables of social investment}

In this exercise, empirically observable attributes or variables for social investment are defined. For each variable, I define three settings. The variable settings are constructed to measure policy regulations, and are related to youth and unemployment risk. These are admittedly rather crude variables given the scope of the concept. To illustrate different types of efforts toward youth unemployment in diverging country contexts, four policies for unemployed youth have been selected to exemplify the operationalisation. These represent policies for unemployed youth, from the policy areas social insurance, labour market and education: The Activity Compensation $(\mathrm{AC})^{2}$ and the Job Guarantee for youth (UGA) ${ }^{3}$ in Sweden, the Federal Act on Vocational Education and Training (VPETA) ${ }^{4}$ in Switzerland and the New Deal for Young People (NDYP) ${ }^{5}$ in the UK. While the differences in type of programme would perhaps not be ideal for an empirical study, for this exercise the broad variety is a conscious choice to help test the robustness of the variable settings (Figure 1).

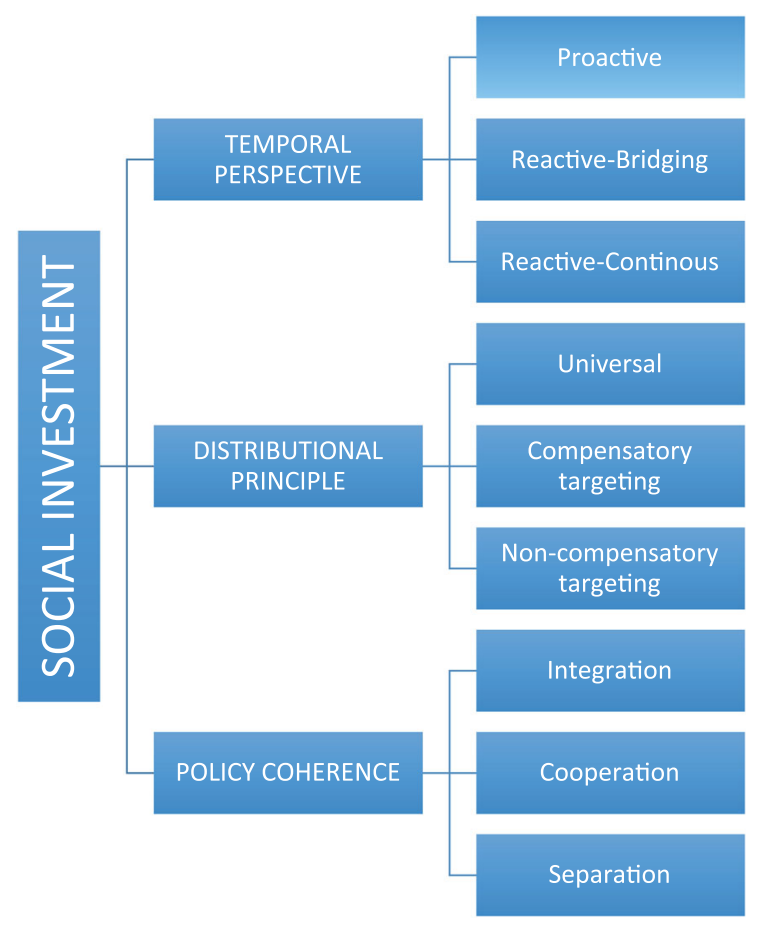

Figure 1. From dimensions of social investment to variables and variable settings. 


\section{Temporal perspective}

The operationalisation of the temporal perspective, is based on two aspects of policies; primarily their point of entry in relation to a social risk, and additionally their duration. The relation between a social risk materialising and the policy response captures the nature of different policy-timelines. It is however key to be mindful of the fact that social risks are defined rather than given, and a policy may address several risks, some of which it may seek to prevent and others react to. For example, day-care may provide a long-term proactive investment for children, as well as a reactive measure for a young parent wanting to seek employment.

The temporal dimension is defined by three variable-settings: Proactive, Reactive-bridging and Reactive-continuous. The point of entry is defined by whether or not a policy is conditioned by a risk having occurred. Proactive policies have no requirement of a risk occurring (e.g. basic education) whereas reactive policies only enter in after a risk is manifested (e.g. unemployment-benefits). The variable value Proactive is solely defined by point of entry. Focusing on young people and the risk of unemployment, the bulk of proactive measures are likely education and child-care, efforts which in Europe generally span over several years. A further distinction by duration of proactive policies is therefore not made in this operationalisation.

Reactive policies on the other hand is divided by duration into the variable-settings Reactive-bridging or Reactive continuous, based on the emphasis in the social-investment literature on policies reacting to 'transitions periods', implying temporary states of volatility. An attempt to pin-point a limit between long- and short term duration runs the risk of being misleading, as it needs to capture characteristics of policies in different areas and include both cash and in-kind measures. Instead, I differentiate between time-limited or non-time-limited measures. The distinction simply being that a reactive policy with a specified maximum duration is defined as a Reactive-bridging policy, and those without as Reactive-continuous. While a bridging approach is more in line with the complementary reactive policies described in the social investment literature, the reactive continuous approach is rather an extension of the bridging approach than a complete divergence from it.

A proactive policy targeting youth unemployment is Switzerland's national legislation for vocational training from 2002 (VPETA). The vocational training programmes are open to youth whether previously unemployed or not and aims to provide smooth transitions from education to employment. The Swedish Job Guarantee for youth (UGA) and Activity Compensation (AC) as well as the UK New Deal for Young People (NDYP) are instead examples of labour market programmes targeting already unemployed youth. Participation in all three programmes is time limited making them reactive-bridging.

\section{Distributional principle}

The distributional principle is tied to notions of equality and distribution, in this case the distribution of policy access for youth and the risk of unemployment. Since the distributional principle of social investment comprises broadly distributed policies, and policies aimed specifically at marginalised individuals or groups, the operationalisation is focused on policy access. Studying the width or curtness of policy access and the individuals it addresses, makes it possible to discern the previously mentioned what, who and 
whom of the distributional principle. How access to a policy is regulated reflects the different forms of equality applied in this article, roughly one that distributes equally (universal) or one that targets those affected negatively by inequality (targeted). This in turn tells us something about the extent and form of responsibility that lie with state and individual/ family respectively.

The distributional principle has the variable-settings: Universal, Compensatory targeting and Non-compensatory targeting. The first indicator, Universal, is defined here as policies available to young people on equal terms, for example an ALMP programme for all youth formally registered as unemployed for a specified time. This includes policies combining general universal access with favourable access conditions for a marginalised group. Compensatory targeting are policies where general access is targeted toward a group of youth, defined as being more vulnerable on the labour market than youth in general. ${ }^{6}$ In cases of cash-benefits, means testing is also defined as compensatory targeting. Finally, Non-compensatory targeting refers to instances where access to a policy is directed to youth who are not marginalised, for example apprenticeship-programmes for youth with high skills. Non-compensatory targeting is treated as a non-equal approach to distribution of access, as it deviates markedly from the other two approaches and from the ideational content of social investment. Sanctions have been left out of the operationalisation due to the difficulty of fully capturing it in regulations, and as they are likely to be found in a large number of policies regardless of universal or targeted access. Access to a policy does not guarantee equal utilisation of it, nor equal or increased advantages because of it. But it does indicate whether there is an intent to equally provide the opportunity for some mode of action (Campbell (1975), and whether there is an effort to level the playing field in the consequences or risk of unemployment for young people.

Three of the four previously mentioned programmes have a universal distributional principle. The VPETA law on vocational training encompasses vocational training broadly, covering upper secondary and tertiary education levels. The UGA and NDYP similarly are directed to a broad group of youth; all registered unemployed youth. The Swedish AC on the other hand is a compensatory-targeting programme, where access is targeted to marginalised youth who have a reduced working capacity.

\section{Policy coherence}

Policy coherence is limited here to regulations on how coordination of implementing agencies is organised. ${ }^{7}$ Given the variety of problems and policies covered by social investment, it is likely that coordination of policy-providing agencies will be important. Since coordination implies seeking some mode of harmony in interaction, it is assumed for this operationalisation that coordination provides important conditions for policy coherence. The variable-settings are created to capture formal regulations of coherence regarding implementing organisations and policy programmes. Implementing organisations in this instance refers to those organisations with the overall responsibility for implementation of a policy/policy area. Due to the quite general description of policy-coherence in the social investment literature, these aspects were selected based on the policy level of interest (policy regulations), and literature on developments in the organisation of policy provision around Europe. 
The variable-settings for coherence are defined as: Integration, Cooperation and Separation. An approach to coherence, uniting two or more agencies or policies under joint leadership constitutes integration (Christensen \& Fimreite, 2010; Øverbye et al., 2009). Cooperation is identified when cooperation is stated in the regulation either as a requirement or explicitly encouraged, even when the structure for such cooperation is not expressly stated or suggested. The third setting, Separation, refers to one of two things; splitting up policies or implementing organisations, which can be exemplified by the outsourcing of public programmes to private actors. Alternatively, when a position on cooperation is wholly absent in the regulations of a policy.

The VPETA reflects an integration form of policy coherence, gathering fields and levels of vocational education that were previously divided between cantons and federal state under a common federal law. Another example of integration is in the UK where the Benefit Agency and Employment Service were merged into Job Centre Plus, an integrated agency delivering benefits and services of the NDYP. The Swedish UGA on the contrary contains no regulations requiring or encouraging cooperation. In addition, the Swedish Public Employment Services (PES) were tasked with purchasing services from private providers to be used for example in UGA. These two aspects of UGA reflects separation. In the Swedish programme AG, there is a stated responsibility for the implementing agency (the Swedish Social Insurance Agency; SIA) to cooperate with other relevant agencies and actors. This is in line with the setting cooperation (Table 1).

\section{Ideal types of social investment}

The variation of policy approaches in each dimension indicates that the building blocks for a social investment policy may be combined in different ways. Some of these approaches are more salient in the social investment literature, while others do not rhyme with social investment ideas at all. There are two items that I find merit some attention at this point; first of all, can we distinguish ideal-types or profiles of social investment. Secondly, how do these relate to how the concept has been studied so far?

Starting with the extremes, I identify a strict social investment type, combining more salient social investment approaches from each dimension. When the dominating trend is policies that wholly exclude proactive, universal and integrated aspects of policies we

Table 1. Specification of the defined variable settings for social investment.

\begin{tabular}{|c|c|c|}
\hline Variable & Variable-setting & Specification \\
\hline \multirow[t]{3}{*}{ Temporal perspective } & Proactive & Entry without social risk having occurred \\
\hline & Reactive-Bridging & $\begin{array}{l}\text { Entry only after social risk having occurred, regulated maximum } \\
\text { duration }\end{array}$ \\
\hline & Reactive-Continuous & $\begin{array}{l}\text { Entry only after social risk having occurred, no regulated maximum } \\
\text { duration }\end{array}$ \\
\hline \multirow{3}{*}{$\begin{array}{r}\text { Distributional } \\
\text { perspective }\end{array}$} & Universal & Universal access \\
\hline & Compensatory targeting & Access targeted to marginalised groups \\
\hline & $\begin{array}{l}\text { Non-compensatory } \\
\text { targeting }\end{array}$ & Access directed to non-marginalised group \\
\hline \multirow[t]{3}{*}{ Policy coherence } & Integration & Two or more agencies combined into one \\
\hline & Cooperation & $\begin{array}{l}\text { Regulations encouraging OR requiring cooperation between policy } \\
\text { areas/agencies }\end{array}$ \\
\hline & Separation & $\begin{array}{l}\text { Lack of regulation to cooperate OR Requirement to disperse policy } \\
\text { provision }\end{array}$ \\
\hline
\end{tabular}


are instead dealing with non-social investment. As this is more of a default category for the development of my ideal-types, I refrain from discussing the aspects of non-social investment in this exercise. Beyond these two types, I have identified two other ideal-types, a targeted social investment type building on the more complementary approaches to social investment, and a reactive social investment type where the fundamental temporal dimension is reactive rather than proactive, but the distributional principle is universal as in the strict social investment.

The ideal types are illustrated using the four examples of policy responses against youth unemployment from Sweden, Switzerland and the UK.

\section{Strict social investment}

If we distil the more salient approaches from each dimension of social investment we end up with an ideal type based on a proactive timeline, a universal distributional principle, and an integration approach to coherence. This implies a strictly biased form of social investment.

This ideal-type combines pro-active efforts with universal access to policies. It reflects quite an individualistic approach where equal opportunity is not the means to equal outcomes but the goal itself, given that it is applied to proactive policies as opposed to reactive ones. On the other hand, it underscores the necessity of social spending and broad state intervention. The notion of broad proactive measures is the perhaps most salient in the social investment literature. Regarding coherence, the disregard for its role in substantive policymaking is problematic. The way I have operationalised this variable implies that a strict social investment would again, require quite an active state in terms of policy provision and regulating and possibly governing integrated policies. Looking at actual policy areas, basic education systems are to their nature pre-emptive to unemployment, but they may to varying degree be universal and integrated. For example, in the previous section the VPETA is categorised as a proactive, universal and integrated policy type, which is in line with strict social investment. Other education systems, such as those applying tracking, can however not be regarded as universal and is thus further from a strict social investment. This pokes a hole in the presumption in social investment literature that all education efforts are strictly in line with the ideas of social investment. If we look at the NDYP, it is universal and integrated, but has a temporal perspective that is reactive-bridging rather than proactive. This programme corresponds to strict social investment in all aspects but time, which is not surprising as unemployment programmes are based on the substantive risk of being unemployed.

\section{Targeted social investment}

The targeted social investment type is based on a bridging reactive timeline, a compensatory distributional principle and a cooperation approach to coherence. As described in the conceptual framing of the three dimensions, social investment is open to some extent of reactive policies for bridging limited periods of transition. This also implies an openness to compensatory targeting as we are talking about a limited role for these policies. A targeted social investment type opens up for policies that deviate from the strict social investment ideal type, toward the more complementary approaches in social investment. It combines 
a temporal perspective of present spending on present risks, with a restriction on time connecting somewhat to an economic approach to expenditure restrictions. The approach to distribution can be read as reversed from the strict social investment, as targeting to compensate for inequalities is the means to adjust unequal outcomes. In this scenario, the organisational conditions for cooperation act as the means to achieve coherence, implying less public intervention than in the strict social investment. In the literature on social investment, this approach to policymaking is discussed no further than as a complementary policy-format, primarily mentioned in terms of unemployment benefits during transition periods. There are however, examples of other types of policies targeting marginalised youth, as with the AC programme in Sweden. It is targeted to youth with long-term disabilities or illness, cooperation is regulated in the policy, and it is a reaction to inability to gain regular employment. This example demonstrates that reactive social investment policies may well be present in policy areas other than unemployment benefits, a notion that has not been paid much attention in the social investment literature outside the mention of parental leave schemes. The fact that compensatory-targeting is utilised in proactive measures, also begs the question whether the room for compensatory-targeting measures should be paid further attention in the social investment literature.

\section{Reactive social investment}

Based on the goals of social investment, increased inclusion and reduced poverty, it would seem reasonable that some reactive measures would benefit from being universal in order to protect. The reactive social investment type is based on a bridging-reactive timeline as in the targeted social investment, combined with a universal distributional principle of the strict social investment, and a cooperation approach to coherence. The universal approach provides a means of equal opportunities to protection during periods of transition. However, in contrast to the strict social investment, the reactive approach implies the ends to be outcomes that are more equal. This is combined with the responsibility of the state to intervene as inequalities materialise. Policy coherence is here sought through regulated cooperation. Given the complementary role of reactive policies in social investment, and the time-limited nature of these policies, a less invasive form for coherence may be sufficient. However, it does still imply some extent of public intervention through regulation to insure that policies do not counteract one another. This idealtype, where the reactive form of policy is extended by its distributional principle to function as a universal policy, is an attempt to further the notion of the role of reactive policies. Given that the problem to which a policy reacts is not too widespread, it is quite possible for a reactive policy to be universal without supplanting proactive universal policies. The Swedish UGA is an example of a reactive universal policy response. This programme is universal in access, and has a specified time limit, categorising it as a bridging-reactive policy. However, it lacks the cooperation aspect of the reactive social investment; instead, the UGA is characterised by separation. In this sense, the UGA demonstrates that policies that may entail several features in line with a social investment strategy can also incorporate elements that deviate from social investment.

Scholars argue that social investments may be found in many different policy areas (Kvist, 2015b), occurring in variations of different approaches (Bonoli, 2009), and that these are not a package of inseparable strategies in substantive policies (Vandenbroucke 
\& Vleminkx, 2011). This is demonstrated by the examples of policies in different areas, using varying approaches, and to different extent belonging to an ideal-type of social investment. In previous studies on social investment, education is often categorised as social investments per se because it is proactive. Yet as demonstrated, education efforts may lack approaches that are central to social investment, begging the question when and how is education actually social investment? Another reoccurring concept is equality of opportunity, which we may find both in education but also in reactive measures such as the Swedish job guarantee for youth or the NDYP. In addition, the role of equal outcomes and protection is described in the literature as having a complementary role to play, yet it is hardly mentioned outside examples such as unemployment benefits and parental leave. This could be interpreted to mean that other reactive measures, such as the AC in Sweden, are not social investments, in spite an approach to increased equality, a focus on human capital investment and cooperation focus. In order to measure and debate social investment in a more nuanced and structured manner we need to study several approaches and how they interact. We also need to move beyond the notion that a specific type of policy, such as education, is always social investment. I argue that we need to open up to the idea of several types of social investment, as well as the fact that these may be more or less suitable for addressing different problems, in different policy areas and for different groups.

\section{Conclusions}

Social investment is in terms of welfare-state paradigms, still a fairly new concept. It does draw on neo-liberal and even more so Keynesian welfare state ideas. In fact, part of the divergence between the two has more to do with different application of those notions in social investment. One could see the social investment concept as a shift of Keynesian politics from primarily demand-side intervention and investment, to primarily supplyside intervention and investment. As with most concepts seeking to carry a new welfare state agenda or paradigm, the accuracy of such a description naturally varies with when and where it is implemented, as exemplified through the described ideal types.

This article makes two main contributions; first of all the operationalisation of social investment is applicable to studies using policy documents as data, in other words it moves beyond the focus on expenditure data which has so far been one of the dominating traditions in studies on policy development. What this demonstrates is the benefits from differentiating between approaches to social investment in order to be able to measure the presence of social investment in policies rather than policy types or areas. By doing so, we can in a more refined way learn to what degree the ideational content of policies belong to different types of social investment. This brings me to the second contribution; it creates a framework for measuring variation of social investment characteristics represented in policies. This provides us with a more nuanced understanding of how policies may be approaching different social investment strategies, and in addition providing a basis for critically examining and further developing the concept as such.

When applying this operationalisation to empirical cases, I believe a few items merit some attention here. In terms of topics, further studies are needed on current examples of social investment in times of for example economic crises as well as incoherent labour market regulations, which may lead to interesting variations in social investment 
strategies. Future research would also benefit from focusing on additional areas of social and welfare state policy. However, this article is a strive in the quest to better measure to what degree, and in what form, such translation has actually occurred. To learn whether ideas of social investment are actually present in substantive policies. It is a first essential step to the further evaluation and debate on the possible gains and risks of social investment.

\section{Notes}

1. It should be noted that this does not negate that there are also several other areas of welfare state and social policy which are of relevance for studies of social investment, and deserve attention.

2. The AC is a programme for unemployed youth with long-term reduced work capacity, providing benefits and the opportunity for activities that maintain or facilitate rehabilitation of work capacity.

3. The UGA is a labour market programme from 2007 for youth registered as unemployed for 3 months. Benefits are conditioned upon participation. The programme contains job-support, training and education for a maximum of 15 months.

4. The VPETA from 2002 gathers regulations for all vocational training and education on upper secondary and tertiary level under a common federal law.

5. The NDYP is a labour market programme from 1999 for youth registered as unemployed for 6 months. Benefits are conditioned upon participation. The programme contains jobsupport, training and education and has varying maximum duration for different options in the programme.

6. When applying this operationalisation to empirical cases, the position of different sub-groups of youth on the labour market for the country or region in question must be individually assessed.

7. While implementation of coordination is naturally also relevant, it goes beyond the scope of this operationalisation.

\section{Acknowledgements}

The author thanks Renate Minas and Åke Bergmark for invaluable comments and guidance, and Tomas Korpi and Joakim Palme for valuable comments.

\section{Disclosure statement}

No potential conflict of interest was reported by the authors.

\section{Notes on contributor}

Lisa Andersson has been a doctoral researcher in social work since 2013 and has also worked on an EU funded European research project on resilience in labour market policies post the economic crisis. Her research interests include: Social policy, youth unemployment and comparative policy studies.

\section{References}

Atkinson, A. B. (2010). Poverty and the EU: The new decade. Macerata: Macerata University. (Macerata lectures on European economic policy, Working paper no. 24). 
Beland, D. (2016). Ideas and institutions in social policy research. Social Policy and Administration, 50(6), 734-750.

Bengtsson, M., de la Porte, C., \& Jacobsson, K. (2017). Labour market policy under conditions of permanent austerity: Any sign of social investment? Social Policy and Administration, 51(2), 367-388.

Bonoli, G. (2007). "Too narrow and too wide at once": The welfare state as a dependent variable in policy analysis. In J. Clasen \& N. Siegel (Eds.), Investigating welfare state change: The 'dependent variable' problem in comparative analysis (pp. 24-39). Cheltenham: Edward Elgar.

Bonoli, G. (2009). Varieties of social investment in labour market policy. In N. Morel, B. Palier, \& J. Palme (Eds.), What future for social investment (pp. 55-66). Stockholm: Institute for Future Studies.

Bothfield, S., \& Roualt, S. (2014). Families facing the crisis: Is social investment a sustainable social policy strategy. Social Politics: International Studies in Gender, State \& Society, 22, 60-85.

Bouget, D., Frazer, H., Marlier, E., Sabato, S., \& Vanhercke, B. (2015). Social investment in Europe: A study of national policies (European social policy network (ESPN)). Brussels: European Commission.

Campbell, T. D. (1975). Equality of opportunity. Proceedings of the Aristotelian Society, 75, 51-68.

Cantillon, B. (2011). The paradox of the social investment state: Growth, employment and poverty in the Lisbon era. Journal of European Social Policy, 21(5), 432-449.

Cantillon, B. (2013). Beyond social investment. Which concepts and values for social policy-making in Europe?Paper for the annual ESPAnet conference, September 5-7 2013, Poznan University of Economics, Poland.

Cantillon, B., \& van Lancker, W. (2013). Three shortcomings of the social investment perspective. Social Policy and Society, 12(4), 553-564.

Christensen, T., \& Fimreite, A.-L. (2010). Nav in an international context (Report 1-2010). Bergen: Uni Rokkan Centre.

Deeming, C., \& Smyth, P. (2015). Social investment after neoliberalism: Policy paradigms and political platforms. Journal of Social Policy, 44(2), 297-318.

de la Porte, C., \& Jacobsson, K. (2012). Social investment or re-commodification? Assessing the employment policies of the EU member states. In N. Morel, B. Palier, \& J. Palme (Eds.), Towards a social investment welfare state? Ideas, policies and challenges (pp. 117-150). Bristol: The Policy Press.

Dworkin, R. (1981a). What is equality? Part one: Equality of welfare. Philosophy \& Public Affairs, 10 (3), 185-246.

Dworkin, R. (1981b). What is equality? Part two: Equality of resources. Philosophy \& Public Affairs, 10(4), 283-345.

Ellison, M., \& Fenger, M. (2013). Social investment, protection and inequality within the new economy and politics of welfare in Europe. Social Policy \& Society, 12(4), 611-624.

Esping-Andersen, G., Gallie, D., Hemerijck, A., \& Myles, J. (2002). Why we need a new welfare state. Oxford: Oxford University Press.

European Commision. (2011). Eu indicators in the field of youth. Brussels: European Union: European Commission. (Commision staff working document 401).

Giddens, A. (1998). The social investment state. In A. Giddens (Ed.), The third Way: Renewal of social democracy (pp. 99-128). Cambridge: Polity Press.

Hemerijck, A. (2011). The social investment imperative beyond the financial crisis. Brussels: European Policy Centre. (Challenge Europe 21: 11-19).

Hemerijck, A. (2012). Two or three waves of welfare state transformation. In N. Morel, B. Palier, \& J. Palme (Eds.), Towards a social investment welfare state? Ideas, policies and challenges (pp. 3360). Bristol: The Policy Press.

Hemerijck, A. (2015). The quiet paradigm revolution of social investment Social Politics: International Studies in Gender, State \& Society, 22(2), 242-256.

Jenson, J. (2009). Redesigning citizenship regimes after neoliberalism. Moving towards social investment. In N. Morel, B. Palier, \& J. Palme (Eds.), What future for social investment? (pp. 27-44). Stockholm: Institute for Future Studies. 
Kouitto, K. (2016). From social security to social investment? Compensating and social investment welfare policies in a life-course perspective. Journal of European Social Policy, 26(5), 442-459.

Kvist, J. (2015a). A framework for social investment strategies: Integrating generational, life course and gender perspectives in the EU social investment strategy. Comparative European Politics, 13 (1), 131-149.

Kvist, J. (2015b). Social investment reforms: Changing paradigms, policies and institutions. Paper for the annual ESPAnet conference, September 3-5 2015. University of Southern Denmark, Odense.

Leoni, T. (2016). Social investment: A guiding principle for welfare state adjustment after the crisis? Empirica, 43, 831-858.

Morel, N., Palier, B., \& Palme, J. (2009). Introduction. In N. Morel, B. Palier, \& J. Palme (Eds.), What future for social investment? (pp. 15-22). Stockholm: Institute for Future Studies.

Nolan, B. (2013). What use is 'social investment'? Journal of European Social Policy, 23(5), 459-468.

Øverbye, E., Strohmeyer Navarro Smith, R., Karjalainen, V., \& Stremlow, J. (2009). The coordination challenge. In Y. Kazepov (Ed.), Rescaling social policies: Toward multi-level governance in Europe (pp. 389-414). Farnham: Ashgate Publishing Limited.

Pintelon, O., Cantillon, B., Van den Bosch, K., \& Whelan, C.-T. (2013). The social stratification of social risks: The relevance of class for social investment strategies. Journal of European Social Policy, 23(1), 52-67.

Sartori, G. (1970). Concept misformation in comparative politics. American Political Science Review, LXIV(4), 1033-1053.

Vandenbroucke, F., Hemerijck, A., \& Palier, B. (2011). The EU needs a social investment pact. Brussels: European Social Observatory. (No. 5, European Social Observatory, Paper Series).

Vandenbroucke, F., \& Vleminkx, K. (2011). Disapointing poverty trends: Is the social investment state to blame? Journal of European Social Policy, 21(5), 450-471.

Van Kersbergen, K., \& Hemerijck, A. (2012). Two decades of change in Europe: The emergence of the social investment state. Journal of Social Policy, 41(3), 475-492.

Van Oorschot, W. (2013). Comparative welfare state analysis with survey-based benefit recipiency data. The dependent variable problem revisited. European Journal of Social Security, 15(3), 224248.

White, L. A. (2012). Must we all be paradigmatic? Social investment policies and liberal welfare states. Canadian Journal of Political Science, 45(3), 657-683. 